\title{
Analysis on the evolution trend of water resources and water environment in Xiangjiang River basin
}

\author{
Xingyi Xu ${ }^{1, a}$, Chuqiu Xiao ${ }^{2}$, Chunyan $\mathrm{Hu}^{1}$, Guiyuan $\mathrm{Li}^{1}$,Xiang Gao ${ }^{3,4}$, Huaiguang $\mathrm{He}^{1}$, Xinkui Wang ${ }^{2}$, Yuqi Pan ${ }^{1}$ \\ ${ }^{1}$ Hunan Institute of Water Resources and Hydropower Research, Changsha, Hunan 410007, China \\ ${ }^{2}$ College of Hydrology and Water Resources, Hohai University, Nanjing, Jiangsu 210098, China \\ ${ }^{3}$ Hunan Provincial Academy of Science and Technology Consulting Co., Ltd., Changsha, Hunan 410004, China \\ ${ }^{4}$ Hunan Academy of Environmental Protection Science, Changsha, Hunan 410004, China
}

\begin{abstract}
According to the daily flow data collected by three representative hydrological stations in the Xiangjiang River basin which are the Guiyang station in the upstream section, the Hengshan station in the midstream section, and the Xiangtan station in the downstream section, and the water environment data collected from the Hunan Water Resources Bulletin, Mann-Kendal method was used to analyze the changes of the annual average flow of the Xiangjiang River basin in the past 20 years as well as the variation of water environment quality in the whole year, flood season and non-flood season. Based on these analysis, the evolution trend of water resources and water environment in the Xiangjiang River basin is further forecasted. The results show that the annual runoff of the upper reaches of the Xiangjiang River basin tends to be stable, and the runoff of the middle and lower reaches is decreasing. The water quality of the Xiangjiang River basin got deteriorated from 1996 to 2010. A sudden change occurred around 2012, and the water quality of the basin gradually improved.
\end{abstract}

\section{Foreword}

Xiangjiang River is an important tributary of the Yangtze River and the mother river of Hunan. Xiangjiang River basin is located in the radiating zone of the Yangtze River Economic Belt and the South China Economic Circle. It is an important grain production base in china ${ }^{[1]}$. The climate in the upper reaches of the Xiangjiang River basin is superior to the climate and soil conditions, and is suitable for the growth of special economic crops, such as the prestigious Jiangyong Xiangyou, the citron, the citrus of Xiangnan, the oil tea, the mint of Yongzhou, the tear bamboo of the Lanshan county, and the magnolia of Dao county. The climate in the lower reaches of the basin is mild, with abundant rainfall, abundant light and heat resources, and fertile land. It is suitable for the growth of major crops such as rice, wheat, corn and cotton. However, cities such as Yongzhou, Hengyang, Zhuzhou, Xiangtan and Changsha in the basin are distributed along the Xiangjiang River, and most of the industries such as metallurgy, chemical industry, building materials, light industry, textiles, food processing and machinery in Hunan province are located in the region. In the past two decades, the process of urbanization and the development of industry and agriculture have had a great impact on the water ecological environment of the basin ${ }^{[2-3]}$. The protection of water ecological environment is a long-term and complex system engineering, and is an effective way to improve the ecological environment value of the basin and the coordinated development of regional economic construction ${ }^{[4]}$. Therefore, this paper uses Mann-Kendall test method ${ }^{[5]}$ to analyze the evolution trend of water ecological environment in Xiangjiang River basin in the past 20 years, in order to provide decision-making basis for the development, utilization and protection of water resources in Xiangjiang River basin, as well as the sustainable development of Xiangjiang River basin economy which is of great significance to the improvement of the water ecological environment.

\section{Overview of the Xiangjiang River basin}

Xiangjiang River is the largest river in Hunan province and the largest tributary of the Dongting Lake water system ${ }^{[6]}$. Its annual average flow into the Dongting Lake is $713,108 \mathrm{~m}^{3}$, accounting for $22.4 \%$ of the total flow into the Dongting Lake. Its flow changes have an significant impact on the water storage in Dongting Lake ${ }^{[7]}$. The length of the main stream of Xiangjiang River is $856 \mathrm{~km}$ and the area of the Xiangjiang River basin is $94,600 \mathrm{~km}^{2}$. The tributaries of the Xiangjiang River include Xiaoshui river, Qishui river, Fulingshui river, Zhengshui river, Leishui river, Mishui river, Lushui river, Liuwei river, Laodao river, Liuyang river, Jinshui river, Weishui river,

\footnotetext{
a Corresponding author: 461416807@qq.com
} 
etc. which are injected into Dongting Lake at Haohe River located in Yiyang. The water system in the basin is very complicated, which has numerous tributaries. There are 2,157 tributaries of over 5km length, including 124 primary tributaries. The two sides of the main stream of the Xiangjiang River are in the form of asymmetrical feathers. The right bank covers an area of $67,316 \mathrm{~km}^{2}$, accounting for $71.2 \%$ of the total area of the basin, where the three major tributaries are Xiaoshui river, Leishui river and Mishui river located on the right bank, with watersheds exceeding $10,000 \mathrm{~km}^{2}$. The left bank covers an area of $27,433 \mathrm{~km}^{2}$, accounting for $28.8 \%$ of the total area of the basin, where the seven major tributaries with a drainage area of more than $1000 \mathrm{~km}^{2}$ are distributed on the left bank, with the largest catchment area is $7155 \mathrm{~km}^{2}$.(Fig. 1 )

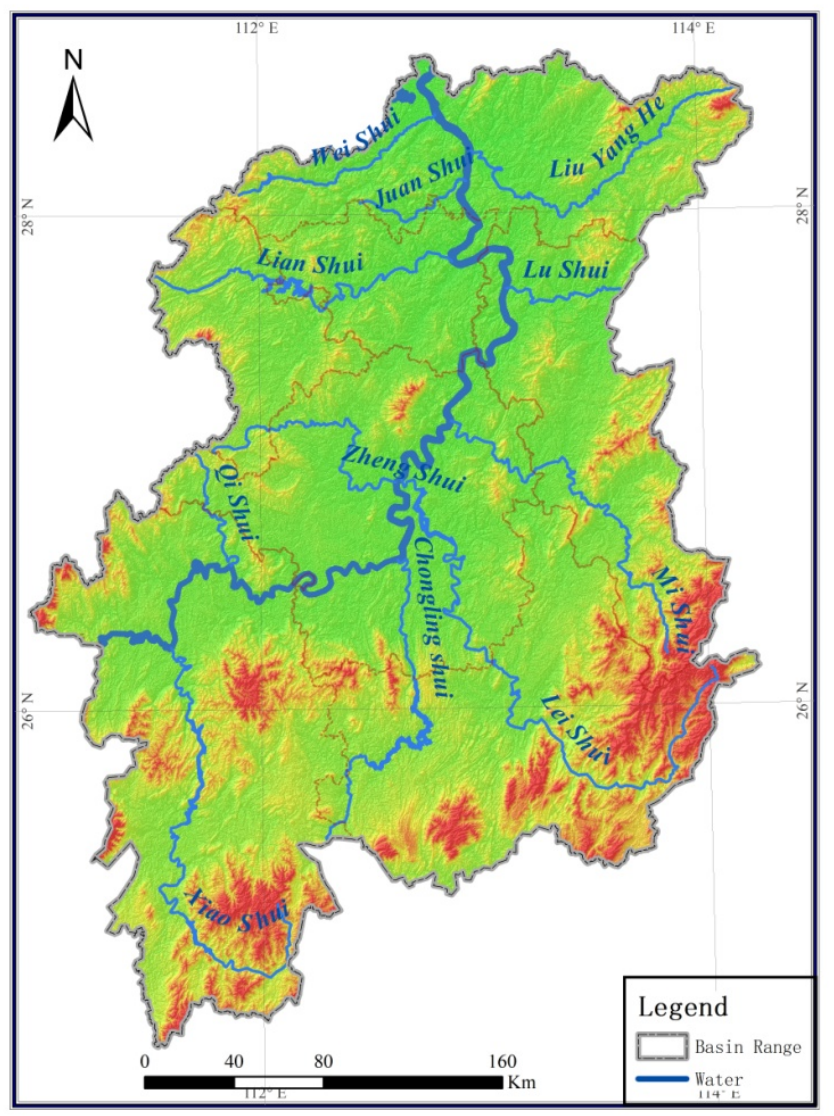

Figure 1. Xiangjiang River basin water system map

\section{Mann-Kendall test method}

Mann-Kendall test method is a nonparametric statistical test method. This method does not require the sample to follow a certain distribution, nor is it interfered with a few outliers, and is more suitable for type variables and order variables. The advantage of this method is that not only the calculation is simple, but also the time at which the mutation starts, and the mutation region is indicated. Therefore, it is a commonly used mutation detection $\operatorname{method}^{[8-10]}$.

Method overview: With a time series $\mathrm{X}$ of $\mathrm{n}$ sample sizes, construct an order column:

$$
\begin{aligned}
& S_{k}=\sum_{i=1}^{k} r_{i} \\
& r_{i}= \begin{cases}1 & x_{i}>x_{j} \\
0 & \text { else } \quad j=1,2, . ., i\end{cases}
\end{aligned}
$$

The rank sequence $S_{k}$ is the cumulative number of the number of values at the $\mathrm{i}$-th time when the value is greater than $\mathrm{j}$. The statistic UF is defined under the assumption that the time series is randomly independent.

$$
U F_{k}=\frac{s_{k}-E\left(s_{k}\right)}{\sqrt{\operatorname{Var}\left(s_{k}\right)}} \quad k=1,2, \ldots, n
$$

Where $\mathrm{UF}_{1}=0, \mathrm{E}\left(\mathrm{S}_{\mathrm{k}}\right), \operatorname{Var}\left(\mathrm{S}_{\mathrm{k}}\right)$ is the mean and variance of the cumulative number $S_{k}$. When $x_{1}, x_{2}, \ldots, x_{n}$ are independent of each other and have the same continuous distribution, they can be calculated by the following formula:

$$
\begin{aligned}
E\left(s_{k}\right) & =\frac{n(n+1)}{4} \\
\operatorname{Var}\left(s_{k}\right) & =\frac{n(n-1)(2 n+5)}{72}
\end{aligned}
$$

$\mathrm{UF}_{\mathrm{i}}$ is a standard normal distribution, which is a statistic sequence calculated in time series $x_{1}, x_{2}, \ldots, x_{n}$. Given a significance level $\alpha$, check the normal distribution table, if $\left|\mathrm{UF}_{\mathrm{i}}\right|>\mathrm{U}_{\alpha}$, it indicates that there is a significant trend in the sequence.

Repeat the above process in time series $\mathrm{x}, \mathrm{x}_{\mathrm{n}}, \mathrm{x}_{\mathrm{n}-1}, \ldots, \mathrm{x}_{1}$, and make $\left.\mathrm{UB}_{\mathrm{k}}=-\mathrm{UF}_{\mathrm{k}}, \mathrm{k}=\mathrm{n}, \mathrm{n}-1, \ldots, 1\right), \mathrm{UB}_{1}=0$.

Calculation begins:

(1) Calculate the order column $\mathrm{S}_{\mathrm{k}}$ of the sequential time series and calculate $U_{\mathrm{k}}$ according to the equation.

(2) Calculate the order column $S_{k}$ of the reverse-order time series, and also calculate $\mathrm{UB}_{\mathrm{k}}$ according to the equation.

(3) Given a significance level, such as $\alpha=0.05$, then the critical value $U_{0.05}= \pm 1.96$.

Analysis of results: If the value of $U_{k}$ or $U_{k}$ is greater than 0 , it indicates that the sequence is increasing; if the value of $U_{k}$ or $U B_{k}$ is less than 0 , it indicates that the sequence is decreasing; when the value of $U F_{k}$ or $U_{k}$ exceeds the range of the critical value line $\mathrm{U}_{0.05}= \pm 1.96$, the trend of rising or falling is significant. The range exceeding the critical line is determined as the time zone in which the mutation occurs. If there is an intersection point between the two curves of $\mathrm{UF}_{\mathrm{k}}$ or $\mathrm{UB}_{\mathrm{k}}$, and the intersection point is between the critical lines, the corresponding time of the intersection point is the mutation start time ${ }^{[11]}$.

\section{Analysis of the evolution trend of water resources}

The evolution trend of water resources in the Xiangjiang River basin is analyzed by analyzing the interannual variation of annual runoff in the Xiangjiang River basin. The study collected the daily runoff from 1996 to 2016 
for the three hydrological stations of the Guiyang station in the upper reaches of the Xiangjiang River basin, the Hengshan station in the middle reaches of the control station, and the Xiangtan station in the downstream section, and calculated the annual average flow series. The specific data is shown in Table 1.

Table 1. Annual average flow series of upper-middle and lower-stream rivers in Xiangjiang River basin from 1996 to 2016 Unit: $10^{3} \cdot \mathrm{m}^{3} / \mathrm{s}$

\begin{tabular}{|c|c|c|c|c|}
\hline Year & Guiyang & Hengshan & Xiangtan & average value \\
\hline 1996 & 1.25 & 1.69 & 2.11 & 1.68 \\
\hline 1997 & 1.42 & 2.36 & 2.76 & 2.18 \\
\hline 1998 & 0.97 & 2.15 & 2.77 & 1.96 \\
\hline 1999 & 0.77 & 1.58 & 1.99 & 1.45 \\
\hline 2000 & 0.79 & 1.52 & 2.19 & 1.50 \\
\hline 2001 & 0.87 & 1.59 & 2.16 & 1.54 \\
\hline 2002 & 1.43 & 2.41 & 3.14 & 2.33 \\
\hline 2003 & 1.14 & 1.51 & 1.97 & 1.54 \\
\hline 2004 & 1.14 & 1.12 & 1.64 & 1.30 \\
\hline 2005 & 1.25 & 1.77 & 2.10 & 1.71 \\
\hline 2006 & 1.32 & 2.27 & 2.42 & 2.01 \\
\hline 2007 & 0.91 & 1.79 & 1.65 & 1.45 \\
\hline 2008 & 0.85 & 1.51 & 1.81 & 1.39 \\
\hline 2009 & 0.96 & 1.16 & 1.55 & 1.23 \\
\hline 2010 & 1.40 & 1.76 & 2.38 & 1.85 \\
\hline 2011 & 0.67 & 0.90 & 1.21 & 0.93 \\
\hline 2012 & 1.30 & 1.75 & 2.25 & 1.77 \\
\hline 2013 & 1.25 & 1.74 & 2.03 & 1.67 \\
\hline 2014 & 0.90 & 1.54 & 1.98 & 1.47 \\
\hline 2015 & 1.22 & 2.04 & 2.37 & 1.88 \\
\hline 2016 & 1.10 & 2.21 & 2.75 & 2.02 \\
\hline
\end{tabular}

The Mann-Kendall method was used to analyze the annual average flow of rivers in the upper and lower reaches of the Xiangjiang River basin and the entire river basin from 1996 to 2016 and reflect their respective evolution trends. Given a significance level $\alpha=0.05$, which means that $\mathrm{U}_{0.05}= \pm 1.96$. The calculation results are shown in Figures 2 to 5.

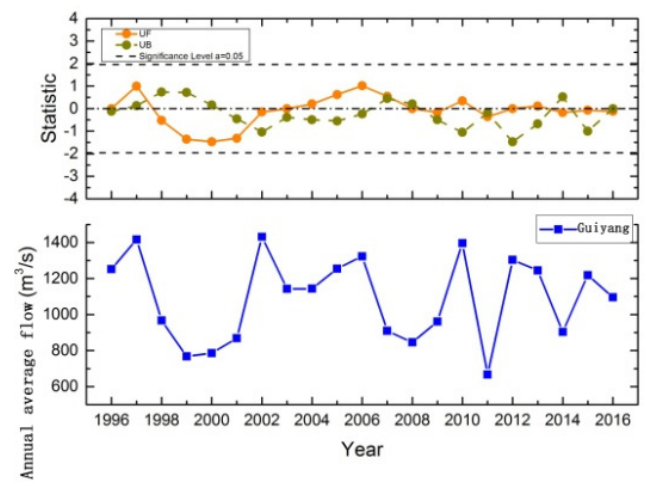

Figure 2. MK mutation test of annual average flow in Guiyang Station in the upper reaches of Xiangjiang River basin

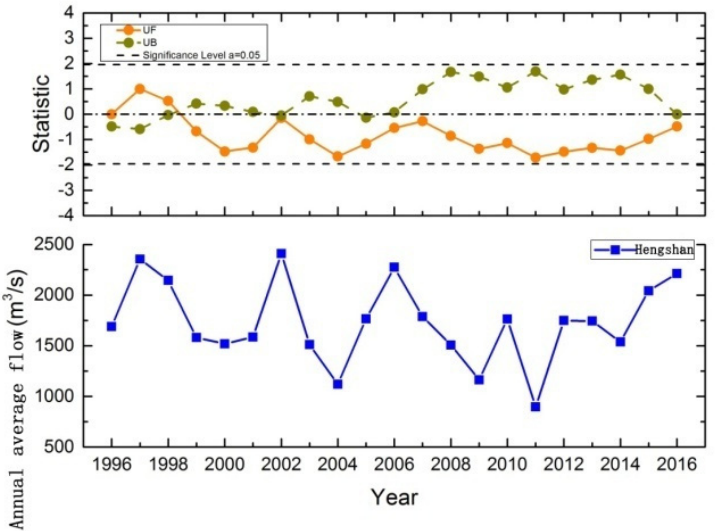

Figure 3. MK mutation test of annual average flow rate of Hengshan station in the middle reaches of Xiangjiang River basin

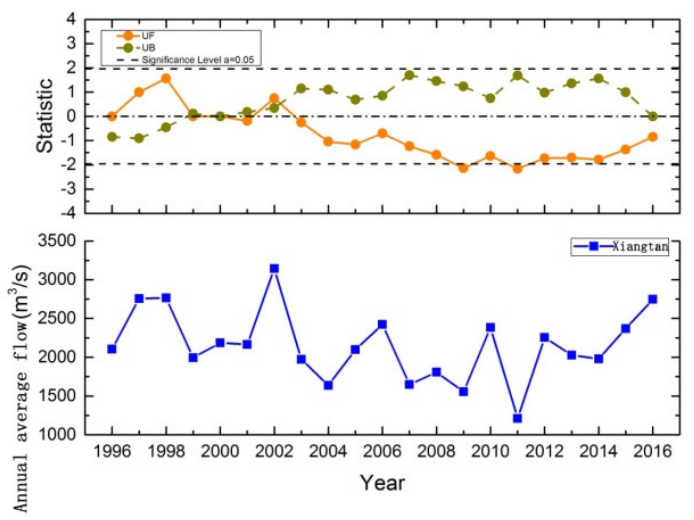

Figure 4. MK mutation test of annual average flow of Xiangtan station in the lower reaches of Xiangjiang River basin

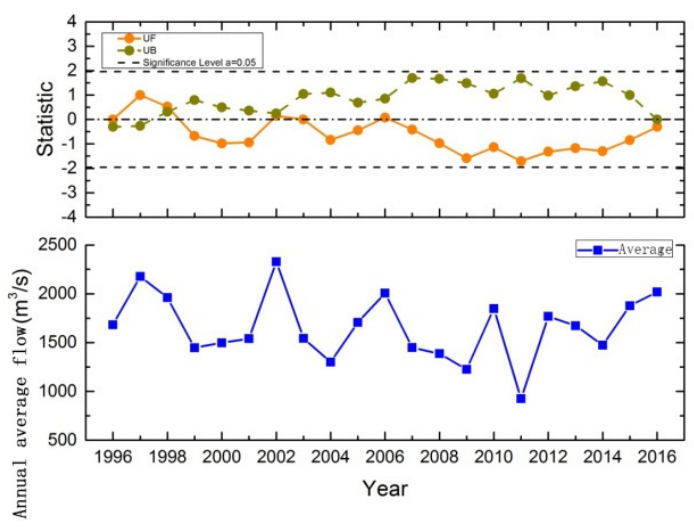

Figure 5. MK mutation test of average annual flow mean value of three hydrological stations in Xiangjiang River basin

According to the UF curve in Figure 2, the UF value is less than 0 in 1996-2001, indicating that the runoff in the upper reaches of the Xiangjiang River basin is decreasing during this period. The UF value is greater than 0 in 2002-2006, indicating that the runoff in the upper reaches of the Xiangjiang River basin is increasing during this period. The UF value is close to 0 in 2007-2016, indicating that the runoff in the upper reaches of the Xiangjiang River basin has remained basically 
unchanged during this period. In general, since the UF value is less than $\mathrm{U}_{0.05}$ and is closer to 0 , this indicates that the upstream runoff in the Xiangjiang River basin did not change significantly during the study period.

According to the UF curve in Figure 3, the UF curve of the Xiangjiang River basin is basically maintained below 0 , which indicates that the overall runoff of the middle reaches in the Xiangjiang River basin is decreasing. According to the position of the intersection of the UF and UB curves, it can be judged that the decline of the runoff in the Xiangjiang River basin is a mutation phenomenon, and this mutation occurred around 1998.

According to the UF curve in Figure 4, the UF curve in the lower reaches of the Xiangjiang River basin is similar to that in the middle reaches, and its value is basically maintained below 0 . This indicates that the overall runoff of the lower reaches of the Xiangjiang River basin is decreasing. According to the location of the intersection of UF and UB curves, the decline of runoff in the lower reaches of the Xiangjiang River basin is also a mutation phenomenon. This mutation occurred around
1998 and is basically consistent with the situation in the Xiangjiang River basin.

According to the UF curve in Figure 5, since 1998, the UF value of the entire river basin has remained below 0 , indicating that the overall runoff in the Xiangjiang River basin is decreasing. According to the intersection of the UF and UB curves, 1998 is the point of mutation. This is also consistent with previous conclusions. The overall decline in water volume in the basin is mainly caused by the decline in runoff in the middle and lower reaches.

\section{Analysis of the evolution trend of water environment}

The analysis of the evolution of water environment is reflected by analyzing the multi-year changes in the proportion of rivers in the II and III water quality. The study collected data on the proportion of rivers in the II and III water quality of the Xiangjiang River from 1996 to 2016. The specific data is shown in Table 2. (Data from the Hunan Provincial Water Resources Bulletin)

Table 2. Table of water quality of Xiangjiang River from 1996 to 2016

\begin{tabular}{|c|c|c|c|c|}
\hline \multirow[t]{2}{*}{ Year } & \multicolumn{3}{|c|}{ The proportion of Grade II and III water quality in the evaluation of } & \multirow[t]{2}{*}{ Major pollutants in the Xiangjiang River basin } \\
\hline & full year & flood season & Non-flood season & \\
\hline 1996 & $94.50 \%$ & $81.50 \%$ & $80.00 \%$ & ammonia nitrogen, arsenide, volatile phenol, $\mathrm{COD}, \mathrm{BOD}_{5}$, total mercury, etc. \\
\hline 1997 & $47.10 \%$ & $47.90 \%$ & $54.00 \%$ & ammonia nitrogen, volatile phenol, total mercury, etc. \\
\hline 1998 & $87.23 \%$ & $91.20 \%$ & $75.80 \%$ & $\begin{array}{c}\text { ammonia nitrogen, volatile phenol, heavy metals such as arsenic, mercury and } \\
\text { cadmium }\end{array}$ \\
\hline 1999 & $54.90 \%$ & $79.60 \%$ & $42.20 \%$ & total mercury, ammonia nitrogen, total cadmium, volatile phenol, COD, etc. \\
\hline 2000 & $74.57 \%$ & $70.00 \%$ & $62.70 \%$ & total mercury, ammonia nitrogen, total arsenide, petroleum, total coliform, etc. \\
\hline 2001 & $83.56 \%$ & $87.20 \%$ & $76.80 \%$ & total mercury, ammonia nitrogen, total cadmium, total arsenide, petroleum, etc. \\
\hline 2002 & $67.54 \%$ & $70.40 \%$ & $76.90 \%$ & $\begin{array}{l}\text { fecal coliform, total phosphorus, ammonia nitrogen, mercury, cadmium, arsenic, } \\
\text { volatile phenol, permanganate index, etc. }\end{array}$ \\
\hline 2003 & $52.00 \%$ & $69.40 \%$ & $34.20 \%$ & $\begin{array}{l}\text { fecal coliform, total phosphorus, ammonia nitrogen, mercury, hexavalent chromium, } \\
\text { cadmium, volatile phenol, permanganate index, etc. }\end{array}$ \\
\hline 2004 & $64.19 \%$ & $66.50 \%$ & $65.40 \%$ & $\begin{array}{l}\text { fecal coliform, ammonia nitrogen, cadmium, total phosphorus, volatile phenol, } \\
\text { dissolved oxygen, fluoride, permanganate index, etc. }\end{array}$ \\
\hline 2005 & $71.60 \%$ & $75.10 \%$ & $60.80 \%$ & $\begin{array}{l}\text { fecal coliform, ammonia nitrogen, cadmium, total phosphorus, volatile phenol, } \\
\text { dissolved oxygen, arsenic, permanganate index, petroleum, etc. }\end{array}$ \\
\hline 2006 & $54.60 \%$ & $53.60 \%$ & $62.20 \%$ & $\begin{array}{l}\text { fecal coliform, ammonia nitrogen, cadmium, total phosphorus, volatile phenol, } \\
\text { dissolved oxygen, arsenic, petroleum, etc. }\end{array}$ \\
\hline 2007 & $65.30 \%$ & $70.30 \%$ & $62.10 \%$ & $\begin{array}{l}\text { fecal coliform, ammonia nitrogen, total phosphorus, volatile phenol, dissolved } \\
\text { oxygen ,petroleum, etc. }\end{array}$ \\
\hline 2008 & $68.50 \%$ & $71.00 \%$ & $67.70 \%$ & $\begin{array}{l}\text { fecal coliform, ammonia nitrogen, total phosphorus, volatile phenol, dissolved } \\
\text { oxygen, petroleum, etc. }\end{array}$ \\
\hline 2009 & $70.80 \%$ & $72.20 \%$ & $70.00 \%$ & fecal coliform, ammonia nitrogen, total phosphorus, dissolved oxygen, petroleum, etc. \\
\hline 2010 & $70.30 \%$ & $70.30 \%$ & $70.10 \%$ & $\begin{array}{l}\text { fecal coliform, ammonia nitrogen, total phosphorus, volatile phenol, dissolved } \\
\text { oxygen, petroleum, etc. }\end{array}$ \\
\hline 2011 & $94.70 \%$ & $97.80 \%$ & $89.20 \%$ & ammonia nitrogen, petroleum, total phosphorus, dissolved oxygen, etc. \\
\hline 2012 & $94.30 \%$ & $93.10 \%$ & $91.10 \%$ & ammonia nitrogen, petroleum, total phosphorus, dissolved oxygen, etc. \\
\hline 2013 & $98.80 \%$ & $98.20 \%$ & $96.90 \%$ & ammonia nitrogen, total phosphorus, etc. \\
\hline 2014 & $98.30 \%$ & $98.70 \%$ & $95.70 \%$ & $\begin{array}{l}\text { ammonia nitrogen, total phosphorus, volatile phenol, petroleum, dissolved oxygen, } \\
\text { etc. }\end{array}$ \\
\hline 2015 & $98.70 \%$ & $99.10 \%$ & $96.60 \%$ & ammonia nitrogen, total phosphorus, petroleum, dissolved oxygen, etc. \\
\hline 2016 & $98.50 \%$ & $99.40 \%$ & $95.20 \%$ & ammonia nitrogen, total phosphorus, volatile phenol, petroleum, etc. \\
\hline
\end{tabular}


The Mann-Kendall method was used to analyze the water quality mutations and their respective evolution trends in the three periods of the Xiangjiang River basin during the whole year, the flood season and the non-flood period from 1996 to 2016. Given a significance level $\alpha=$ $0.05, \mathrm{U}_{0.05}= \pm 1.96$. The calculation results are shown in Figures 6 to 8 .

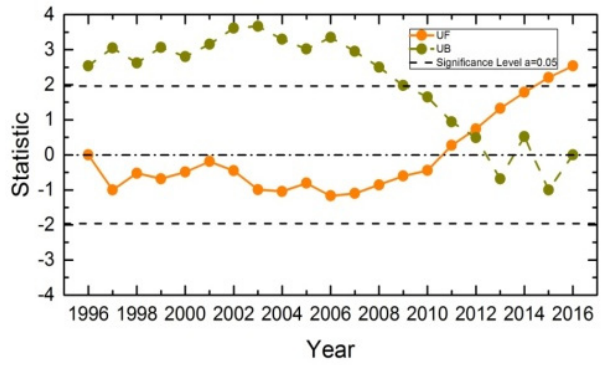

Figure 6. MK mutation test of the proportion of the II and III water quality in river in the full year

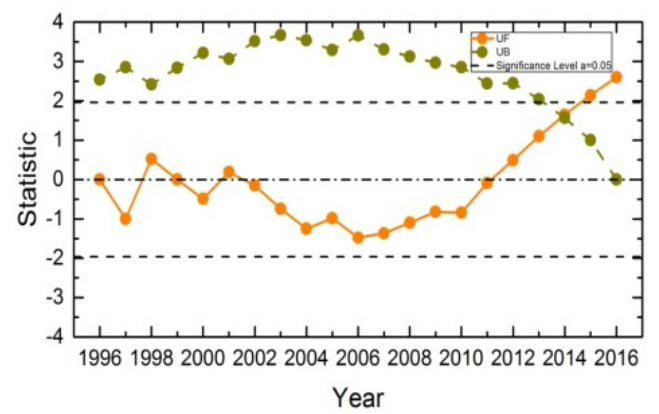

Figure 7. MK mutation test for the proportion of the II and III water quality in river in the flood season

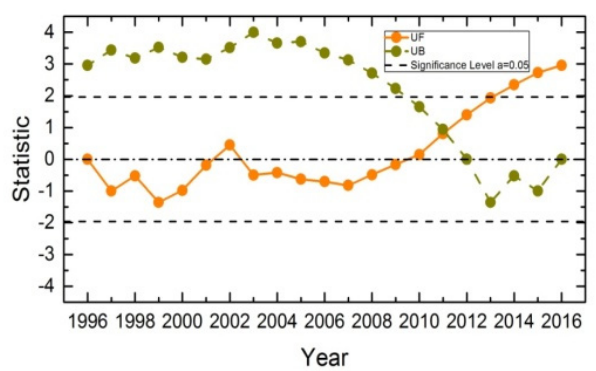

Figure 8. MK mutation test for the proportion of the II and III water quality in river in the non-flood season

According to the UF curve of the whole year of Figure 6, the UF value from 1996 to the end of 2010 is maintained below 0 , indicating that the water quality of the Xiangjiang River basin is deteriorating during the 14-year period. During this period, due to urban construction, mining, farmland irrigation, etc. a large number of industrial sewage, agricultural water withdrawal and domestic garbage discharge, resulting in serious pollution of heavy metals in the Xiangjiang River basin, fecal coliform, volatile phenol, ammonia nitrogen, total phosphorus and chemical aerobic The indicators such as quantity exceeded the standard, the aquatic biodiversity decreased, the water environment quality of the Xiangjiang River basin was poor, and the ecological environment was threatened. Since 2011, the UF value is greater than 0 , and the water quality of Xiangjiang River has improved. The UF line and the UB line intersect at a significant level of 0.05 in 2012, and the intersection point exists in the 1.96 confidence interval. This indicates that the improvement of the water quality in Xiangjiang River is a sudden phenomenon. Since the end of 2012, the water quality of the Xiangjiang River has gradually improved.

According to the UF curve of the flood season in Figure 7 and the UF curve of the non-flood period in Figure 8 , the UF values of both of them remained below 0 at the end of 1996 to the end of 2010, indicating that the water quality of the Xiangjiang River basin showed a deteriorating trend during the 14-year period. According to the location of the intersection of UF and UB curves, the improvement of water quality in Xiangiiang River is a mutation phenomenon. Specifically, the water quality mutation in the flood season started in 2014, and the water quality mutation in the non-flood period started in 2011.

According to Figures 6 to 8 , combined with the MK test of three periods, the long dashed line in the figure indicates that the critical value is positive or negative 1.96 , which means that the test with a significance level of $95 \%$, and the UF or UB with an absolute value greater than 1.96 indicates that the trend is significant. In each period of approximately 17 years, the water quality growth trend exceeded the critical level of 0.05 critical line. This indicates that the rising trend of water quality in the Xiangjiang River basin in recent years is very significant. The water quality improvement projects in the basin have achieved initial results, and the water ecological environment in the Xiangjiang River basin is constantly improving. Exploring the cause, we find that Hunan Province has adopted many methods to control the Xiangjiang River. On September 27, 2012, Hunan Province officially passed the "Regulations on the Protection of Xiangjiang River in Hunan Province", which marked the first comprehensive local regulations on the protection of river basins in China; in 2013, Hunan launched the "No.1 Key Project" for the implementation of Xiangjiang River protection and treatment. It plans to implement three "three-year action plans" and the implementation of five key tasks, focusing on strengthening river management, strengthening water resources security, and strengthening water resources management. In the end, it will achieve the overall goal of "mountain clear, shore green, river smooth, water net", and urge the people of the province to pay more attention to, work harder and more effectively protect the mother 
river of Xiangjiang. It can also be seen from the MK test chart that the "Xiangjiang No.1 Key Project" has achieved great success and the water environment quality of the Xiangjiang River basin has been greatly improved.

\section{Conclusion}

In this paper, the MK mutation test method was used to analyze the annual runoff data of the Xiangjiang River basin in the past 20 years and the trend data of the II and III water quality. The results show that the annual runoff of the upper reaches of the Xiangjiang River basin tends to be stable and the scope of change is small. The runoff of rivers in the middle and lower reaches is declining, and this decline in runoff is a sudden phenomenon, which occurred around 1998. The water quality of the Xiangjiang River basin has been deteriorating throughout the 14-year period from 1996 to 2010, and the water quality is poor. Since 2011, the water quality of the basin has been continuously improved. This water quality improvement is also a sudden phenomenon, which occurred around 2012. In recent years, the improvement trend of water quality in the Xiangjiang River basin is very significant.

In the future, for the protection of water resources and water environment in the Xiangjiang River basin, it is still necessary to continue to strengthen the control and treatment of watershed pollution ${ }^{[12]}$. On the one hand, it is necessary to optimize and adjust the local industrial structure, develop clean energy, and reduce emissions of pollutants in industrial and agricultural production; on the other hand, it is necessary to strengthen the system management of water environmental protection, and the various departments and industries involved in water environmental protection. To unify, build an integrated model for comprehensive improvement of the water environment in the Xiangjiang River basin, and realize unified planning and comprehensive management of the Xiangjiang River basin.

\section{Acknowledgement}

This study is based on the following Hunan Water Conservancy Science and Technology Project support:

Research on the water ecological security index system of Xiangjiang River basin, contract number: Xiangshui Science and Technology [2015] 186-21;

Research on performance evaluation and benign operation mechanism of urban water ecological civilization construction, contract number: Xiangshui Science and Technology [2016] 194-37.

\section{References:}

1. Zuo Xiaojuan, Yu Yong, Zhu Fang. Effects of tourism development on soil heavy metals and water conditions in Xiangjiang River Basin [J]. Journal of Soil and Water Conservation, 2015, 29(06): 263-270.

2. Zhang Z, Tao F, Du J, et al. Surface water quality and its control in a river with intense human impacts: A case study of Xiangjiang River, China [J]. Journal of Environmental Management, 2010, 91 (12): 2482-2490.

3. Zhang Q, Li Z, Zeng G, et al. Assessment of surface water quality using multivariate statistical techniques in red soil hilly region: A case study of Xiangjiang watershed, China [J]. Environmental Monitoring and Assessment, 2009, 152 (1/4): 123-131.

4. Wang Shengrui, Shu Yumin, Ni Zhaokui, Feng Minglei, Liu Zhigang, Pang Yan, Fang Hongya. Investigation on the current situation of water pollution in Poyang Lake and its prevention and control measures [J]. Journal of Environmental Engineering Technology, 2013, 3(04): 342-349.

5. Zhang BQ, He CS, Burnhamc M, et al. Evaluating the coupling effects of climate aridity and vegetation restoration on soil erosion over the Loess Plateau in China [J]. Science of the Total Environment, 2016, 539: 436- 449.

6. ZHANG Qiang, CHEN Guiya, XU Chongyu, et al. Characteristics of water and sediment cycle in the Yangtze River Basin and possible causes of impact [J]. Advances in Water Science, 2009, 20(1): 80-85.

7. Mao Dehua, Li Jingbao, Gong Chonghui, et al. Research on flood disasters in Hunan Province [M]. Changsha: Hunan Normal University Press, 2000.

8. Kendall M G.Rank correlation measures [M]. London: Charles Griffin, 1976: 110-120.

9. Mann H B. Non-parametric tests against trend $[\mathrm{J}]$. Econometrica, 1945, 13: 245-259.

10. Hu Guangwei, Mao Dehua, Li Zhengmao, Xu Wei. Analysis of Evolution Process and Characteristics of Runoff Sediment in Xiangjiang River from 1951 to 2011 [J]. Bulletin of Soil and Water Conservation, 2014, 34(01): 166-172.

11. KISI O, AY M. Comparison of Mann-Kendall and Innovative Trend Method for Water Quality Parameters of the Kizilirmak River, Turkey [J]. Journal of Hydrology. 2016, 513(26): 362-375.

12. Wang Yanfen, Ni Zhaokui, Lin Ripeng, Guo Shuzhen, Wang Shengrui, Li Xiaoxiu. Characteristics of water environment evolution and identification of key influencing factors in Dongting Lake [J]. Journal of Environmental Science, 2018, 38(07): 2254-2259. 